“Historical Studies on Mortality," special issue, Canadian Studies in Population 39, no. 3-4 (2012): $123-124$.

\title{
Ethnicity and Integration
}

\author{
edited by John Stillwell and Maarten van Ham \\ Heidelberg: Springer, 2010 \\ ISBN 978-90-481-9102-4 \\ Hardcover, €171.15, 320 pp.
}

\author{
Reviewed by Ann H. Kim \\ Department of Sociology, York University, Toronto \\ annkim@yorku.ca
}

Immigrant-receiving societies often contend with arguments that ethnic and racial diversity leads to fragmentation, segregation and increased social tensions. This edited collection is a response to the perception that the impact of diversity on British society is negative and that the UK is "sleepwalking [its] way to segregation" (p. 133). Public and political discourse paints a grim picture, fueled by violent events in Britain's past, and undoubtedly most recently after the police shooting of a Black male, Mark Duggan, sparked violent riots in London in early August 2011. The book is an attempt to balance the sensationalistic and alarmist discourse by examining the empirical evidence on the link between diversity and integration using representative data from censuses and national surveys. As a whole, the collection tells a more hopeful story; that diversity and social cohesion are not negatively associated; and that racial and ethnic groups in British society are integrating for the most part, yet at their own pace.

Consisting of fourteen quantitative chapters that centre on ethnic and racial diversity, themes include population change, internal migration and residential concentration, household dynamics, identity and language, physical health, victimization, social cohesion, and population projections. Four chapters (Finney pp. 27-46; Sabater pp. 47-62; Stillwell and Hussain pp. 105-32; Simon pp. 133-52) dispel fears that segregation is on the rise and seek to explain changes in the ethnic composition of local areas and neighbourhoods by examining fertility rates, age structures, and internal migration rates. These descriptive chapters remind us that residential patterns are to be viewed as a process, not as static indicators of intergroup relations, and we learn that spatial segregation among ethnic and racial groups is on a gradual decline. The analyses show that ethnic minority groups tend to have higher internal migration rates than whites, which can be explained in part by their relatively younger age structures. They also show minority group members as moving away from areas of high co-ethnic concentration, and the tendency of new immigrants to move to areas of low minority concentration.

Together, the four chapters provide thorough descriptions of Britain's residential landscape; however, the explanations offered often view residential movement and settlement as "choices." This leaves the reader questioning how structural, institutional and ecological dimensions, such as housing development, housing discrimination and racial residential steering, may have factored into the patterns observed. A more in-depth discussion of processes at this level would have significantly added to this literature on segregation in the UK context.

A related key theme is the effect of the geographic context in terms of ethnic, racial or immigrant composition. To address concerns that spatial concentration necessarily leads to deleterious and disintegrative outcomes, five chapters investigate how neighbourhood and/or areal composition, measured in various ways, is associated with outcomes such as intermarriage with whites (Feng et al. pp. 83-104), labour market outcomes (Shaginyan-Shapira pp. 153-78), health, experiences of racial discrimination, and civic engagement (Stafford et al. pp. 225-50), victimization, fear of crime and perceptions of the criminal justice system (Kautt pp. 251-68), and social cohesion (Stafford et al. pp. 225-50; Taylor et al. pp. 269-88).

So, what can be said of the impact of racial and ethnic spatial concentration? The multiple ways in which areal boundaries and characteristics were operationalized by each of the authors of the five chapters make it problematic 
to compare and compile findings. The various spatial scales used in the studies include wards to Middle Super Output Areas (MSOA) to districts to Criminal Justice Areas (CJA) to regions. To complicate matters, the degree of diversity of the different areas was also captured in myriad ways - from percent co-ethnic to the application of the Theil entropy index-demonstrating that clarity in the concept and definition of diversity is needed in research that explores theoretical linkages between diversity and social cohesion, and diversity and integration. Despite such limitations, which can be explained in part by the datasets used in the different studies, we can conclude that there is no sweeping generalization to be made.

Rather, we learn that the effect of ethnic, racial or immigrant concentration, or diversity, on the experiences of the more populous groups (e.g., White, Black-Caribbean, Black-African, South Asian Indian, Pakistani, Chinese, and Bangladeshi), in terms of their personal lives, the labour market, and their fears and perceptions, are as varied as the geography, indicators, analytical methods, and datasets applied. For example, while it hinders interethnic marriages with Whites, it has a positive effect on the wages and occupational attainment of British-born residents. Second, while it has a positive effect on social cohesion for Indian, Caribbean and Bangladeshi residents (but not African or Chinese residents), it has no association with civic participation. Third, while it has a negative association with collective efficacy in the neighbourhood, it has no association with the perception of anti-social behaviour in the neighbourhood.

Such divergent outcomes will make it challenging for policymakers, for whom the book seems to be written, which may explain the paucity of policy recommendations in the book. The editors acknowledge there is a bipolar way of thinking about diversity — as conflict-inducing versus an aspect of society to be celebrated, but make the point that Britain has shifted from being a country of emigration to one of immigration and as such must view ethnic integration as a two-way process with new residents and host communities adapting to one another. Yet, how this might translate into policy is left open to consideration.

The remaining chapters complete the collection by focusing less on the neighbourhood or regional context and more on ethnic distinctions. As with Canada's ethnic and racial groups, the groups in the UK vary in terms of their fertility rates (Dubuc and Haskey pp. 63-82), physical activity and obesity (Higgins and Dale pp. 203-24) and population projections (Norman et al. pp. 289-316). Moreover, as Mitton and Aspinall's (pp. 179-202) study shows, which is in line with other studies on internal diversity in Canada and the United States, broad racial and panethnic categorizations mask the diversity of experiences of national origin groups. In other words, they find significant differences among Black African ethnic groups in terms of their integration experiences. The implications of their results should be considered in future work on racial, ethnic and immigrant integration in the UK and elsewhere.

Overall, this collection is a gold mine for researchers in geography, sociology, and demography due to the application of quantitative and demographic methods as well as to the variety of data sources described and analyzed. At the same time, however, the content is less accessible to a lay audience, and for one unfamiliar with UK data, the sheer range of datasets and geographies render it difficult to follow the chapters from one to the next. Nevertheless, one interested in the UK census, Labour Force Survey (LFS), Office of National Statistics (ONS) Longitudinal Study, Annual Population Survey, Individual Controlled Access Microdata Sample (CAMS), Health Survey for English (HSE), Citizenship Survey, British Crime Survey (BCS), National Survey of Sexual Attitudes and Lifestyles II, or Millennium Cohort Study, will find a study in this collection that has benefited from the opportunities offered by the data and suffered from their limitations.

It must also be stated that with these data, much knowledge has been gained, and to have a comprehensive source on diversity in the British context is highly advantageous for graduate students, policymakers, researchers and academics alike. More importantly, however, is how this knowledge will be translated to politicians and the wider public when they are ready to engage in the "sociological debate" about the origins of the recent violence in London, a discussion that Deputy Prime Minister Nick Clegg is reported to have told BBC radio is for the future. 